\title{
Effects of memory strategy training on performance and event-related brain potentials of children with ADHD in an episodic memory task
}

Citation for published version (APA):

Jonkman, L. M., Hurks, P. P., \& Schleepen, T. M. J. (2016). Effects of memory strategy training on performance and event-related brain potentials of children with ADHD in an episodic memory task. Neuropsychological Rehabilitation, 26(5-6), 910-941. https://doi.org/10.1080/09602011.2015.1070735

Document status and date:

Published: 01/01/2016

DOI:

10.1080/09602011.2015.1070735

Document Version:

Publisher's PDF, also known as Version of record

\section{Document license:}

Taverne

Please check the document version of this publication:

- A submitted manuscript is the version of the article upon submission and before peer-review. There can be important differences between the submitted version and the official published version of record.

People interested in the research are advised to contact the author for the final version of the publication, or visit the DOI to the publisher's website.

- The final author version and the galley proof are versions of the publication after peer review.

- The final published version features the final layout of the paper including the volume, issue and page numbers.

Link to publication

\footnotetext{
General rights rights.

- You may freely distribute the URL identifying the publication in the public portal. please follow below link for the End User Agreement:

www.umlib.nl/taverne-license

Take down policy

If you believe that this document breaches copyright please contact us at:

repository@maastrichtuniversity.nl

providing details and we will investigate your claim.
}

Copyright and moral rights for the publications made accessible in the public portal are retained by the authors and/or other copyright owners and it is a condition of accessing publications that users recognise and abide by the legal requirements associated with these

- Users may download and print one copy of any publication from the public portal for the purpose of private study or research.

- You may not further distribute the material or use it for any profit-making activity or commercial gain

If the publication is distributed under the terms of Article $25 \mathrm{fa}$ of the Dutch Copyright Act, indicated by the "Taverne" license above, 
An International Journal

\title{
Effects of memory strategy training on performance and event-related brain potentials of children with ADHD in an episodic memory task
}

\author{
Lisa M. Jonkman, Petra P. Hurks \& Tamara M. J. Schleepen
}

To cite this article: Lisa M. Jonkman, Petra P. Hurks \& Tamara M. J. Schleepen (2016) Effects of memory strategy training on performance and event-related brain potentials of children with ADHD in an episodic memory task, Neuropsychological Rehabilitation, 26:5-6, 910-941, DOI: 10.1080/09602011.2015.1070735

To link to this article: https://doi.org/10.1080/09602011.2015.1070735

Published online: 07 Aug 2015.

Submit your article to this journal ¿

Џll Article views: 966

Q View related articles $\sqsubset$

View Crossmark data \ulcorner

Citing articles: 1 View citing articles $[7$ 


\title{
ORIGINAL ARTICLE
}

\section{Effects of memory strategy training on performance and event-related brain potentials of children with ADHD in an episodic memory task}

\author{
Lisa M. Jonkman' ${ }^{1}$, Petra P. Hurks², and Tamara \\ M. J. Schleepen ${ }^{1}$ \\ ${ }^{1}$ Faculty of Psychology and Neuroscience, Department of Cognitive \\ Neuroscience, Maastricht University, Maastricht, The Netherlands \\ ${ }^{2}$ Faculty of Psychology and Neuroscience, Department of Neuropsychology \\ and Psychopharmacology, Maastricht University, Maastricht, The \\ Netherlands
}

(Received 27 February 2015; accepted 3 July 2015)

Evidence for memory problems in children with attention deficit hyperactivity disorder (ADHD) is accumulating. Attempting to counter such problems, in the present study children with ADHD aged 8-12 years underwent a six-week metacognitive memory strategy training (MST) or one of two other active trainings, either a metacognitive attention-perceptual-motor training (APM) or placebo training consisting of playing board games (PLA). Effects of the training on episodic memory and underlying brain processes were investigated by comparing performance and event-related brain potentials (ERPs) on preand post-training sessions in an old/new recognition task between the three training groups. Potential far transfer effects of the memory strategy training were investigated by measuring performance on neuropsychological attention and memory-span tasks and parent-rated ADHD symptoms. The metacognitive memory strategy training led to significantly improved memory performance

Correspondence should be addressed to L. M. Jonkman, Faculty of Psychology, Department of Cognitive Neuroscience, Section of Developmental Cognitive Neuroscience, Maastricht University, P.O. Box 616, MD 6200, Maastricht, The Netherlands. E-mail: L.Jonkman@ maastrichtuniversity.nl

No potential conflict of interest was reported by the authors.

This work was supported by the Hersenstichting Nederland (Dutch Brain Foundation) [Grant number: 12F04(2).01].

(C) 2015 Informa UK Limited, trading as Taylor \& Francis Group 
and enhanced amplitude of left parietal P600 activity associated with the process of memory recollection when compared to PLA, but APM training evoked similar improvements. Memory performance gains were significantly correlated with the memory-related ERP effects. Preliminary far transfer effects of MST training were found on attention and working memory performance and on parent-rated ADHD symptoms, although these results need replication with larger and better IQ-matched groups.

Keywords: Attention deficit hyperactivity disorder; Memory strategy; Cognitive training; Event-related brain potentials; Parietal cortex.

\section{INTRODUCTION}

In diagnostic instruments, like the DSM-5, inattentive disorganised behaviour is still one of the most important criteria for receiving a diagnosis of attention deficit hyperactivity disorder (ADHD; American Psychiatric Association, 2013). However, executive function (EF) deficits, especially working memory problems, have been increasingly reported the past decade in children with ADHD (Karatekin, 2004; Martinussen, Hayden, Hogg-Johnson, $\&$ Tannock, 2005; Stevens, 2005; Willcutt, Doyle, Nigg, Faraone, \& Pennington, 2005). EFs include core cognitive processes such as attention and (working) memory, and also metacognitive knowledge about strategies and tasks that rely on attention and working memory, and are crucial for learning and academic achievement (Meltzer, 2007). Indeed, EF problems have been particularly implicated in reduced learning capacity and academic underachievement in ADHD (Biederman et al., 2004; Johnson \& Reid, 2011).

Accordingly, the past decade has seen a steep rise in the development and application of adaptive cognitive computer training that directly targets one or more of these cognitive/executive core functions thought to be affected in ADHD, mostly working memory (e.g., Cogmed: Klingberg et al., 2005). The promise of such training programs is that by directly affecting brain circuitry underlying such core functions they will be more effective in remediating behavioural, cognitive, and/or learning problems that rely on the same brain areas (Rapport, Orban, Kofler, \& Friedman, 2013). Recent studies, reviews and meta-analyses, however, show that such working memory training does enhance working memory capacity, but has no or only weak and inconsistent far transfer effects on academic performance or behaviour symptoms, such as inattention, in children with low working memory capacity or ADHD (Dunning, Holmes, \& Gathercole, 2013; Melby-Lervåg \& Hulme, 2013; Rapport et al., 2013; Shipstead, Redick, \& Engle, 2012).

One of the reasons for this lack of far transfer effects of computerised working memory training to academic skills in children might lie in the fact 
that such training often includes tasks that primarily rely on short-term visuospatial or phonological memory stores and only requires simple memory strategies such as phonological rehearsal. The acquisition of higher academic skills, such as reading and mathematics, however, also depends strongly on the capacity to explicitly learn and apply more complex memory strategies. Especially the more complex elaborative memory strategies, such as narratives, semantic organisation, grouping or chunking, have strong and enduring effects on learning and memory. These strategies rely on retrieval of information from long-term memory that subsequently has to be processed and integrated with new information in working memory (Ericsson \& Kintsch, 1995). The attachment of meaning to new, to-be-learned, material by linking it to information stored in long-term memory (LTM) has been shown to lead to deeper encoding (Craik \& Lockhart, 1972), and may thus be assumed also to have potentially larger generalising effects on learning and other academic activities.

Compared to simple strategies such as rote rehearsal, more complex elaborative encoding strategies are only spontaneously applied relatively late in childhood (Pressley \& Levin, 1977; Rohwer, Raines, Eoff, \& Wagner, 1977; Schleepen \& Jonkman, 2012, 2014). This delayed developmental pattern seems, at least for an important part, to be due to elaborative strategies demanding more executive resources/working memory capacity hence relying on prefrontal/parietal cortex development that also shows protracted maturation throughout childhood/adolescence (Bunge \& Wright, 2007). Because working memory/executive function deficits are known to be a core symptom of $\mathrm{ADHD}$, this is expected to have consequences for the ability of children with ADHD to effectively use elaborative memory strategies. Indeed, previous studies in 7-12-year-old boys and adults with ADHD have provided evidence for a failure to apply elaborative, working memory demanding, verbal memory encoding strategies such as cumulative rehearsal (O'Neill \& Douglas, 1996) or semantic organisation (August, 1987; Cornoldi, Barbieri, Gaiani, \& Zocchi, 1999; Egeland, Johansen, \& Ueland, 2010; Roth et al., 2004). Such deficits in strategic verbal learning/ memory have been suggested to be one of the most important contributors to academic underachievement in children with ADHD (Frazier, Youngstrom, Glutting, \& Watkins, 2007), and EF problems are thought to play a crucial role in this (Johnson \& Reid, 2011). These findings fit with reports that children with ADHD have problems particularly in memory tasks demanding high working memory capacity (needed for the application and learning of verbal rules or strategies) and not so strongly in memory tasks relying on phonologal short-term stores and simple rehearsal (Karatekin, 2004; Martinussen et al., 2005; Rapport et al., 2008; Willcutt et al., 2005). Thus, considering the above, explicit training of elaborative memory strategies is expected to not only improve memory performance, but also is expected to have the potential for generalisation effects on academic skills. 
Indeed, in typically developing children, next to improvement in memory tasks (Moely et al., 1992; Schleepen \& Jonkman, 2012, 2014) explicit cognitive strategy instruction has been reported to have positive transfer effects on reading (Paris \& Oka, 1986) and mathematics problem solving (Swing, Stoiber, \& Peterson, 1988). Also, memory strategy instructions have been reported to be particularly valuable for less skilled learners such as middle aged children and adolescents (Brehmer, Li, Müller, Oertzen, \& Lindenberger, 2007; Moely et al., 1992; Shing, Werkle-Bergner, Li, \& Lindenberger, 2008). Finally, there is also evidence that children with ADHD performed better on verbal learning/memory tasks after receiving prompts or cues (August, 1987; Cornoldi et al., 1999; Voelker, Carter, Sprague, Gdowski, \& Lacher, 1989; Whitaker, Bell, Houskamp, \& O'Callaghan, 2015). One recent study trained memory strategies more elaborately in typically developing 5-8-year-old children through a computer programme called Memory Booster (St Clair-Thompson, Stevens, Hunt, \& Bolder, 2010). Positive effects of the training were reported on verbal short-term and working memory, following classroom instructions, and on classroom mental arithmetic performance, no effects were however found on standardised measures of reading and mathematics. Surprisingly, despite its potential breadth of impact, to the best of our knowledge no longer duration explicit memory strategy training studies have yet been performed in children with ADHD.

To fill this gap, the main aim of the present preliminary study was to investigate whether memory strategy training leads to improved memory recollection in children with ADHD and whether this goes along with specific changes (plasticity) in underlying memory-related brain processes (e.g., ERPs). Based on recommendations by Shipstead et al. (2012), besides a memory strategy training group, the present study included two active, instead of no-contact, control groups. The first was an active placebo training group included to rule out the possibility that memory strategy training effects were (partly) explained by potential positive influences of trainer-child contact. In the second active control group ADHD children received attention perceptual motor training to check for the specificity of memory strategy training effects (Colom et al., 2010). To measure effects of memory strategy training on episodic memory performance an old/new picture recognition task was used. The advantage of this task is that it has been frequently used in ERP research and thus has well-established memory-related ERP effects. The task requires participants to memorise a series of pictures of familiar objects during a study phase. During a subsequent test phase, they have to decide which of the objects in a second series of sequentially presented pictures (now including memorised and new ones) were presented before (old items) or not (new items). Participants usually react faster and more accurately when rejecting new items than when correctly recognising old (memorised) items. This performance difference is caused by the fact that new 
items can be rejected on the basis of their familiarity, a global impression of similarity that requires no memory retrieval, whereas successful old item recognition is based on recollection, requiring the retrieval of memorised information which requires more executive control and more time. Within the ERP signal, two distinct activation patterns have been associated with familiarity and recollection processes in adults (Rugg \& Curran, 2007). A frontal negative peak occurring in a time window between 300 and $500 \mathrm{~ms}$ after stimulus presentation is linked to processes of familiarity because its amplitude is only enhanced when correctly rejecting new items. Memory recollection accuracy (the correct recollection of earlier studied old items), has on the other hand been associated with an enhanced positive peak above parietal scalp areas (also called the P600) occurring 400-600 ms after stimulus presentation. Interestingly, both ERP and fMRI studies have reported higher activity above/in left parietal cortex during successful recollection of earlier learned items when they had previously been encoded more deeply or had higher recollection likelihood (Donaldson \& Rugg, 1998; Henson, Hornberger, \& Rugg, 2005). Accordingly, if memory strategy training leads to deeper encoding, we expect to find an effect on the parietal P600 during the successful recollection of old items. Old/new ERP effects largely similar to those of adults have been reported in children (Cycowicz, 2000).

It was hypothesised that compared to the two active control training strategies, memory strategy training will (1) cause the largest gains in memory performance, measured by training-induced increases in the number of correctly recollected old (earlier encoded) items, and (2) will enhance the amplitude of the parietal ERP (P600) activity associated with successful old item memory recollection processes. Additional standardised neuropsychological attention and short-term and working memory span tests were administered to (1) assure the absence of pre-training differences in short-term and working memory and attention abilities since these have been reported to explain individual differences in strategy use, and (2) to measure potential across-domain generalisation of the memory strategy training. Finally, as a measure of far transfer to behaviour, DSM-based ADHD questionnaires were used to measure potential parent observed training-induced improvements in ADHD symptoms of inattention and hyperactivity/impulsivity.

\section{METHODS AND MATERIALS}

\section{Participants}

Originally, a total of 45 children ( 43 males/ 2 females) with a primary DSMIV ADHD diagnosis given by a psychiatrist or psychologist participated. Complete ERP data were available for 12 children in the memory strategy 
training group (MST; 12 males); 11 children in active control group 1: an attention-perceptual-motor training group (APM; 11 males); and 11 children in active control group 2: a placebo training group (PLA; 10 males/1 female). Dropout was caused by attending fewer than four training sessions $(n=1)$, not completing the pre- or post-training electro-encephalogram (EEG) session $(n=3)$, data with too many artifacts or otherwise noisy data during one of the sessions $(n=4)$, or technical difficulties $(n=3)$. Children were recruited from different Dutch schools (Zuid-Limburg, The Netherlands) that provide special education to children with psychiatric problems; in order to attend these schools children are required to have a psychiatric diagnosis by a child psychiatrist or psychologist. Only children that received a primary DSM-IV ADHD diagnosis by a specialist in the past and had a full-scale IQ above 75 (as assessed by the school psychologist) were included in the study. To further specify the presence of other cognitive and behavioural problems and co-morbidity at the start of the study, the Achenbach System of Empirically Based Assessment (ASEBA; Achenbach \& Rescorla, 2001) was applied by asking parents and teachers to fill out the Child Behavior Checklist (CBCL-6/18) and the Teacher Report Form (TRF-6/18), respectively. The ASEBA method also transforms CBCL and TRF data into DSM-IV classifications and this method has been shown to be reliable in predicting DSM-IV diagnoses in a Dutch population (Krol, De Bruyn, Coolen, \& van Aarle, 2006). See Table 1 for mean $T$-scores on the different CBCL/TRFtransformed DSM classifications and attention and thinking problem scales in the three groups; for DSM scales, a $T$-score between 65 and 69 falls in the subclinical range and a $T$-score of 69 or higher falls in the clinical range (American norms). For other scales $T$-scores between 60 and 63 are sub-clinical and a $T$-score $>63$ is in the clinical range. Furthermore, an additional 18-item, DSM-IV based Dutch ADHD rating scale was administered to the parents (AVL: for reliability and validity see: Scholte, van Berckelaer-Onnes, \& van der Ploeg, 2001). This scale required rating of the presence of inattention, hyperactive and impulsive symptoms at a 5 -point-scale: $0=$ not at all, $1=$ just a little, $2=$ pretty much, $3=$ much, $4=$ very much. All parents and teachers were instructed to rate the children's behaviour when not using medication (such as during weekends or holidays). The pre-training behaviour was rated for the past 6 months, whereas the post-training ratings were based on the present behaviour of the child. The relatively lower problem behaviour ratings of the teachers (indicated by TRF) might be due to less experience with the children in an un-medicated state since most children were on medication during school time. However, teachers' problem ratings were still far above levels reported in typically developing children in comparable studies. The only significant pre-training difference between groups on CBCL and TRF was for affective problems (AFFD), only reported by parents, but not teachers (one-way ANOVA: $p=.013$ ); further testing 
TABLE 1

Subject characteristics (pre-training) in MST, APM and PLA training groups (all children were male, except for one girl in the PLA group)

\begin{tabular}{|c|c|c|c|c|c|c|c|c|}
\hline & \multicolumn{2}{|c|}{$\begin{array}{c}M S T \\
(N=12)\end{array}$} & \multicolumn{2}{|c|}{$\begin{array}{c}A P M \\
(N=11)\end{array}$} & \multicolumn{2}{|c|}{$\begin{array}{c}P L A \\
(N=11)\end{array}$} & \multicolumn{2}{|c|}{$\begin{array}{c}\text { ANOVA } \\
\text { Group effects }\end{array}$} \\
\hline & Mean & SD & Mean & SD & Mean & SD & $\mathrm{F}$ & $\mathrm{p}$ \\
\hline Age (months) & 121.8 & 16.5 & 130.0 & 16.0 & 128.5 & 22.5 & 0.64 & .53 \\
\hline WISC-IQ & 94.9 & 18.2 & 79.6 & 6.5 & 87.8 & 5.1 & 4.75 & $.02^{* *}$ \\
\hline \multicolumn{9}{|l|}{ Parent CBCL ratings* } \\
\hline CBCL-DSM-ADHD & 69.0 & 6.2 & 72.3 & 5.6 & 72.8 & 5.1 & 1.53 & .23 \\
\hline CBCL-DSM-CD & 66.0 & 11.5 & 65.5 & 10.6 & 68.1 & 5.8 & 0.21 & .81 \\
\hline CBCL-DSM-ODD & 67.5 & 7.4 & 66.9 & 7.0 & 68.5 & 6.4 & 0.15 & .86 \\
\hline CBCL-DSM-AFFD & 70.7 & 7.1 & 61.2 & 5.3 & 64.5 & 9.1 & 5.07 & $.01^{* * *}$ \\
\hline CBCL-DSM-ANXD & 65.4 & 7.4 & 57.6 & 6.5 & 62.6 & 8.9 & 2.76 & .08 \\
\hline CBCL-Attention problems & 67.8 & 6.9 & 66.9 & 3.6 & 70.7 & 6.8 & 1.16 & .33 \\
\hline CBCL-Thinking problems & 67.4 & 10.3 & 64.5 & 9.6 & 66.0 & 2.4 & 0.26 & .77 \\
\hline \multicolumn{9}{|l|}{ Parent ADHD-ratings* } \\
\hline Inattention & 16.8 & 4.3 & 14.9 & 5.5 & 17.6 & 5.0 & 0.67 & .52 \\
\hline Hyperactivity & 20.2 & 3.3 & 16.5 & 6.7 & 18.1 & 5.1 & 1.13 & .34 \\
\hline Impulsivity & 18.4 & 4.0 & 14.9 & 6.7 & 16.5 & 5.1 & 0.96 & .40 \\
\hline \multicolumn{9}{|l|}{ Teacher TRF ratings } \\
\hline TRF-DSM-ADHD & 62.2 & 7.7 & 61.4 & 7.3 & 64.4 & 6.1 & 0.52 & .60 \\
\hline TRF-DSM-CD & 62.1 & 9.8 & 62.7 & 9.5 & 62.4 & 8.2 & 0.01 & .98 \\
\hline TRF-DSM-ODD & 63.7 & 6.4 & 61.9 & 7.9 & 64.5 & 6.7 & 0.40 & .67 \\
\hline TRF-DSM-AFFD & 60.5 & 7.1 & 57.2 & 3.6 & 58.6 & 6.5 & 0.88 & .42 \\
\hline TRF-DSM-ANXD & 62.3 & 9.5 & 57.4 & 5.2 & 59.2 & 6.6 & 1.33 & .28 \\
\hline TRF-Attention problems & 61.3 & 10.1 & 59.7 & 6.3 & 62.0 & 5.4 & 0.26 & .77 \\
\hline TRF-Thinking problems & 59.7 & 9.5 & 58.4 & 8.3 & 55.6 & 6.9 & 0.72 & .49 \\
\hline
\end{tabular}

MST $=$ memory strategy, APM = attention-perceptual-motor, PLA = placebo, $\mathrm{CBCL}=$ Child Behavior Checklist, TRF $=$ Teacher Report Form, ADHD = attention deficit hyperactivity disorder, $\mathrm{ODD}=$ oppositional defiant disorder, $\mathrm{CD}=$ conduct disorder, $\mathrm{AFFD}=$ affective disorder, $\mathrm{ANXD}=$ anxiety disorder.

${ }^{*}$ CBCL scores based on $n=11$ in MST and $n=10$ in ATT groups; parent ADHD ratings based on $n=9, n=8$ and $n=10$ in MST, APM and PLA groups.

**IQ only differed between the APM and the other two groups.

***Parents CBCL-AFF score only differed between MST and APM groups.

between groups showed a significantly higher affective disorder score in the memory strategy training group, but only compared to the attention training group (AFFD: $p=.001$ ). Inclusion of CBCL-AFFD scores in the ANOVA did not change the results reported in the results section.

Furthermore, since the full-scale IQ scores obtained by the school psychologist were not always very recent and were sometimes obtained by different IQ tests, IQ was verified before the start of the training by administering two subtests of the Wechsler Intelligence scale for Children-Version III (WISC-III), Vocabulary and Block Design, to all children. The estimated 
total IQ score derived from these subtests has a mean reliability of .94 and a mean validity of .91 compared to the complete WISC-III (Spreen \& Strauss, 1998). Although the IQs of all participants provided by the school psychologist before inclusion in the study were above 75, on the shortened version of the WISC-III, two participants had an IQ below 75 (one subject in the MST group had an IQ of 56 and one participant in the ATT group had an IQ of 68). To not further reduce statistical power it was decided to include these participants in the analyses, which we considered justified because (1) full-scale IQs of these children provided by the school psychologist upon which they were initially included in the study were above 75 , casting doubt on the validity of the IQ estimates that were measured only once in these children in the present study, and (2) neither of the two children appeared to be outliers considering CBCL/TRF scores or scores on the recognition task; in fact, both participants had scores at or above $75 \%$ correct and had normal reaction times on the memory recognition task in the pre-training session. Nevertheless, all ANOVA results reported in the results section were re-computed excluding these two participants and this did not change results.

Children were randomly assigned to the three training groups, matching only on age. All children that used medication had used it for a period of at least 6 months before the start of the study and continued using their regular dose during the entire study. Most children used Ritalin (6, 7, and 5 , respectively, in PLA, ATT, and MST groups), other medications were Concerta (1, 1, and 4 in PLA, ATT, and MST groups, respectively), Dipiperon (1, 1 in PLA and MST groups, respectively), dextroamphetamine (used by 1 child in ATT group), and Risperdal (used by 1 child in the MST group). Finally, there were 3, 2 and 1 children receiving no medication in the PLA, APM and MST groups, respectively; these participants were not outliers considering CBCL/TRF scores or task performance during the pre-session and, importantly, exclusion of these six non-medicated children did not change ANOVA results reported in the results section. Training attendance did not differ significantly between the groups. For an overview of CBCL/TRFbased DSM-IV classifications, IQ, and age in the three groups, see Table 1. All parents signed an informed consent form and the study was approved by a local medical ethical committee.

\section{Procedure}

Children who received a prior DSM-IV diagnosis of ADHD were recruited via their schools. An information letter explaining all the details of the study, accompanied by an informed consent form was sent to the parents of the children. Children were only included in the study when both parents and children assented to the study procedures and when the parents signed an informed consent form. The participating children from each school 
were randomly assigned to one of the three training groups to obtain groups of 3-5 children (group size was kept comparable), matching only on age. Due to the fact that all pre- and post-session measurements and training sessions took part in the schools of the children, children from one school were always placed in a training group with other children from the same school. During pre- and post-training sessions children were tested individually in a quiet room at their school. The pre-training session started by administration of the neuropsychological tests, the data of which are also presented in the present paper. Next, to measure EEG and electro-oculogram (EOG; eyemovements), a 60-channel EEG cap and EOG electrodes were attached while children watched video cartoons. Subsequently children received task instructions (without mention of the strategies that could be used to enhance performance) and performed the two blocks (i.e., study phase and test phase) of the Old/New Recognition task which each lasted approximately 7 minutes (in between and after these blocks they performed other psychophysiological tests, results of which will not be reported here). The session ended with administration of the IQ subtests. The whole session lasted approximately 3 hours. The post-training session was identical to the presession, except that the IQ test was not administered. The children were awarded with a toy as a present after each session. The experimenters that executed pre- and post-training sessions, the teachers, parents and the children themselves were blind to the training type the child was assigned to. In between pre- and post-training sessions children underwent six successive, weekly, group training sessions of 1 hour. All post-training sessions took place within two weeks of the last training session.

\section{Training}

All training was given by a psychologist (the same in all training sessions) and a training assistant, who were not involved in the execution of the pre- and post-training measurements. The exercises that were used in working memory and attention-perceptual-motor training were derived from published educational training (in Dutch) for children with memory and imprinting problems (Timmerman \& van der Schoot, 2001) and children with attention or work-attitude problems (Timmerman, 2004). Also, the stimulus materials in both memory strategy and attention-perceptual-motor training did not overlap with stimuli presented in the Old/New Recognition task.

Both the memory strategy and attention-perceptual-motor training were based on Meichenbaum's international and widely used "general self-instructional approach" (Meichenbaum, 1977). The idea behind this self-instructional approach is that, by formulating questions (e.g., What is the assignment given to us? or What is the best way to deal with this assignment?), seeking out answers and receiving feedback, children increase their 
understanding of the cognitive strategies with which they are acquainted during the training (e.g., rehearsal or organisation of to-be-learned material in the memory training), thereby promoting later spontaneous application of these strategies in relevant situations.

Both memory strategy and control trainings were provided to the children during six weekly group sessions. In the memory strategy and attention-perceptual-motor training, the psychologist provided the assignments in a question and answer format (i.e., primarily paper-and-pencil tasks, which stimulated the children to ask questions verbally and which they can answer by giving either a verbal response (e.g., naming the objects that had to be remembered) or a motor response (by writing down to-be-remembered items or by, for example, drawing a straight line in the attention training). This procedure is in line with the above-mentioned self-instructional approaches. According to Waters (2000), the key to adoption of cognitive skills or strategies (i.e., repeated use in appropriate contexts) seems to be whether the child makes a connection between the particular skill or strategy and performance. Therefore, the psychologist and the training assistant explicitly guided this learning process, by supplying both questions, answers and feedback when needed, but also by stimulating the children, as a group, to search for questions and answers on their own and to evaluate their own work. As mentioned, during and after each assignment, the psychologist and the training assistant provided verbal feedback about the accuracy of the children's responses, but only after the children, as a group, had first evaluated their own work. Additionally, at the end of each assignment, specific feedback was provided concerning the value of the cognitive strategy chosen for the assignment, by asking questions, such as, "Did this strategy improve performance and why?". After each training session, the children further practised the newly learned skills by performing homework that had to be discussed at the next training session.

During the different sessions of the memory strategy training children were taught to apply verbalisation (e.g., by asking them to give specific names to a multiple of 12 pictures of animals, which were provided to them simultaneously on one paper sheet and to remember the name-animal relationship), single item and cumulative rehearsal (e.g., by repeating verbal information of increasing length, ranging from 3 to 15 units, first out loud then whispering, followed by silent repetition), meaningful organisation (e.g., by grouping a multiple of 12 words, pictures or other types of data into meaningful categories, the 12 items were presented on one paper sheet), and verbal elaboration (e.g., by defining a connection between a multiple of 12 to-be-remembered pictures or words, presented on one sheet of paper, by telling a story) strategies. These strategies are applied to information present in working memory and lead to better and more efficient encoding and storage in long-term memory (Timmerman \& van der 
Schoot, 2001). In line with the previously given examples, the amount of information that the children had to process at once was variable (and was always adjusted to the performance level of the child), thereby varying the complexity level of the assignments.

During attention-perceptual-motor training children also performed exercises. These were aimed at improving, for instance, visual-search strategy (e.g., the child has to mark predefined targets among distractors, on pages on which the figures are arranged either in a linear or a random array; the number of figures, including targets and distractors, varied from 26 to 112), eye-hand coordination, including the regulation and monitoring of actions (e.g., draw a line between two printed lines, which differ in terms of distance, varying from 1.5 to $34 \mathrm{~cm}$, direction, either horizontally, vertically, or curved, and total space between the two lines, ranging from 3 to $10 \mathrm{~mm}$ ), and self-evaluation (e.g., the child has to assess his own performance or that of another group member and in case of a mistake he has to think about the causes). The complexity level of the assignments was adjusted to the performance level of the children.

During placebo training children told stories, solved riddles or puzzles, or played different types of board games (Twister, Monopoly). During this training, no specific feedback was provided concerning the value of cognitive functions and/or cognitive strategies that could have been used for the riddles, puzzles, or games. Also, the complexity level of these elements was not adjusted to the performance level of the child.

For all three training types, group motivation and performance was encouraged by employing a reward system in which groups could earn small rewards (stickers) when they solved the problems correctly.

\section{Measures}

For an overview of the complete study design, including all independent and dependent measures see Figure 1.

\section{Computerised Old/New Recognition task}

The episodic (long-term) memory recognition task was identical to that used in a developmental study by Cycowicz, Friedman, Snodgrass, and Duff (2001). The stimuli were 128 line drawings of objects of which norms for children (name agreement, familiarity and visual complexity) are provided by Cycowicz, Friedman, Rothstein, and Snodgrass (1997). Half of the line drawings (64) represented animate objects (i.e., sea creatures, insects, birds, four-footed animals) and the other half inanimate objects (i.e., furniture, clothing, toys, vehicles, kitchen utensils). Four lists were used, each containing pictures of 16 animate and 16 inanimate objects that were carefully equated on category membership, object agreement, familiarity, and visual complexity (for statistics and exact lists see Cycowicz 


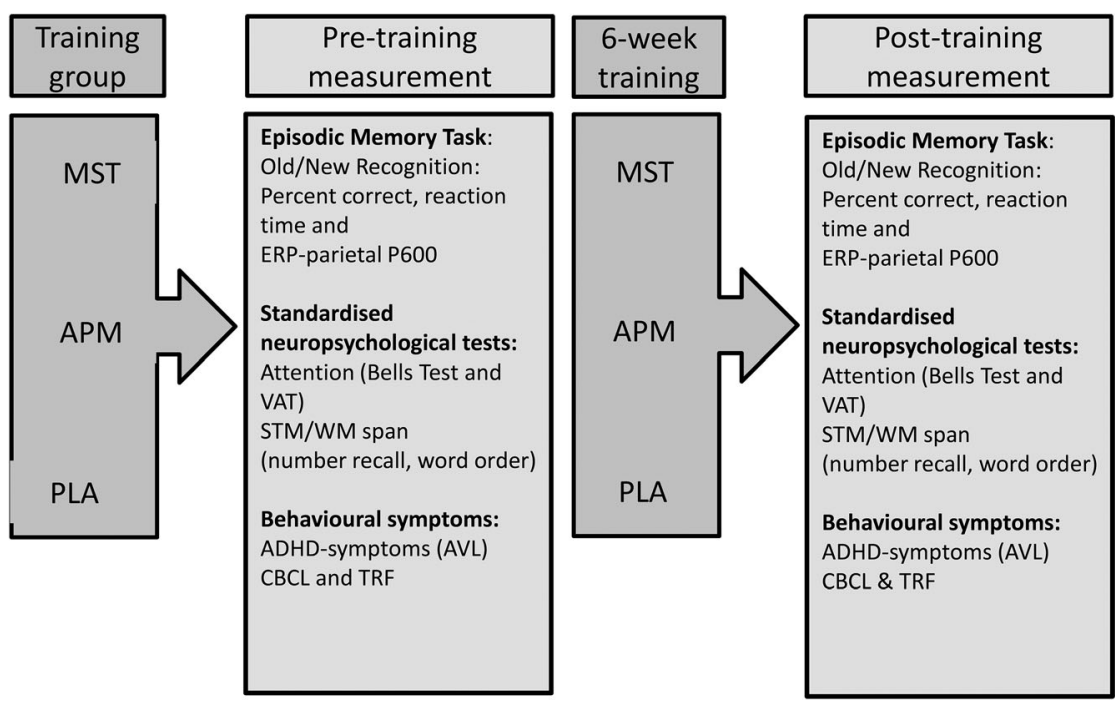

Figure 1. Schematic overview of the study design including all independent (training-groups) and dependent measures (see pre- and post-measurements). MST = Memory strategy training, APM = Attention-Perceptual-Motor training, PLA = placebo training.

et al., 2001). From each list, a set of 16 pictures was selected ( 8 animate and 8 inanimate; equated on category membership across lists) and presented in random sequence during the study phase. To make the children study the items more closely, during the study phase participants had to perform a semantic decision by indicating whether the object was "alive" or "not alive" by pressing a right or left hand button, respectively. To assure that children understood the alive/not alive concept they were asked to give some examples of both types of objects before the start of the task. In addition the children were told to memorise the pictures for a subsequent memory test. In the test phase, the same 16 stimuli (old items) were presented together with the 16 not yet presented (new items) stimuli from the list in random order and participants had to decide whether they had previously seen the stimulus (right button-press) or not (left button-press). During each session (pre- and post-training), two lists (total of 32 new and 32 old items) were presented to the participants. The lists were rotated across participants and training sessions, so that each list was used approximately equally often in all experimental conditions in each group and all participants received all four lists. A restriction was that lists 1 and 3 and lists 2 and 4 were always coupled; thus, if a participant received lists 1 and 3 in the pre-training session, lists 2 and 4 were presented during post-training and vice versa. The order of presentation (i.e., $1-3,3-1$ or $2-4,4-2$ ) of these lists was rotated across participants and pre- and post-sessions within each training group. 


\section{Neuropsychological tests}

Visual attention tasks. Two neuropsychological visual attention tasks were included. Both tests consist of a paper sheet on which target figures are presented amongst distractor figures, both being randomly scattered across the sheet. The participants are instructed to cross out all target figures as fast as possible. Both tasks measure the ability to selectively focus attention on the target stimuli and ignore distractors.

Visual Attention Task (VAT, subtest of a developmental neuropscyhological test battery called the NEPSY; Korkman, Kirk, \& Kemp, 1998). Testretest reliability of this task is .71 in 5-12-year-old children (Kemp \& Korkman, 2010). In the VAT, 20 target figures (cats) are presented amongst 76 non-target figures (objects and other animals) printed on an A3 format sheet.

Bells Cancellation Test (Gauthier, Dehaut, \& Joanette, 2004). This test has a test-retest reliability of .69. It has higher attention demands because of the more condensed presentation of targets (35) and non-targets (315; objects and animals) on a smaller sheet (A4 format), also the target/non-target ratio was smaller in this task.

In both tests the children indicated themselves when they thought they had crossed out all the targets by saying "ready". When they first indicated they had finished, the experimenter asked, "Are you sure you have crossed out all the cats (or bells)?", if the answer was "yes", the time was stopped. Dependent measures were the number of missed targets and the total time they spent on the task (measured by a stop-watch). Only very few false alarms were made so these data were not analysed.

Standardised memory span tests. Two subtests of the Kaufman Assessment Battery for Children (K-ABC; Kaufman \& Kaufman, 1983; Melchers $\&$ Preuss, 1991) were included to test short-term memory/working memory span. The K-ABC subtests included in this study are Number Recall and Word Order (for a description, see below). Average split-half reliability coefficients for these subtests range from .79 to .87 for school-aged children (Kaufman, Lichtenberger, Fletcher-Janzen, \& Kaufman, 2005). Correlation studies revealed an array of evidence for the construct, concurrent, and predictive validity of the K-ABC (Kaufman \& Kaufman, 1983). The K-ABC is designed for testing children aged 2 years 6 months to 12 years 6 months.

Number Recall (NR; Kaufman \& Kaufman, 1983). This is a digit span task measuring short-term memory span, in which series of increasingly longer strings of digits (ranging from 0-10) are presented at a rate of one per second. The child must repeat the digits in the same numerical sequence. The child receives 1 point per correct sequence. The maximum raw score is 22 points. Administration is cut off after three consecutive incorrect answers. 
Word Order (WO; Kaufman \& Kaufman, 1983). This is a cross-modal span task, in which the child has to point to silhouettes of common objects (presented amongst distractor objects) in the same order as the objects were earlier named by the examiner. The child receives 1 point per correct sequence of silhouettes. The maximum raw score is 31 points. Administration is cut off after three consecutive incorrect answers. Due to its combined demands on verbal and visuospatial processing and the suppression of interference from distractors, this task has been named an "executive working memory task" (Dehn, 2008).

For each subtest, standard scores were calculated based on the total number of correct trials while correcting for age $(M=10 ; S D=3$; range: $1-19)$. Since no norm data were available for the Dutch population at the time of testing, the K-ABC norms for German school-aged children were used (e.g., Dopfner et al., 1996).

\section{EEG recording}

The EEG was recorded from 60 tin electrodes that were mounted in a Quickcap at positions: right mastoid, Fp1, Fpz, Fp2, AF7, AF3, AF4, AF8, F7, F5, F3, F1, Fz, F2, F4, F6, F8, FT7, FC5, FC3, FC1, Fz, F2, F4, F6, FT8, T7, C5, C3, C1, Cz, C2, C4, C6, T8, TP7, CP5, CP3, CP1, CPz, CP2, CP4, CP6, TP8, P7, P5, P3, P1, Pz, P2, P4, P6, P8, PO7, PO3, PO4, PO8, O1, Oz, and O2. All electrodes were referenced against the left mastoid and the $\mathrm{AFz}$ electrode of the Quick-cap was used as ground. Vertical EOG was recorded from the supra-orbital and infra-orbital electrodes, placed in line with the pupil of the left eye. Horizontal EOG was recorded from the external canthi of both eyes. All electrode impedances were kept below $10 \mathrm{k} \Omega$. The EEG and EOG measurements were continuously sampled at $500 \mathrm{~Hz}$ with a high-pass filter of 0.05 and a low-pass filter of $120 \mathrm{~Hz}$.

The continuous EEG was divided into epochs of $1750 \mathrm{~ms}$, from $200 \mathrm{~ms}$ pre-stimulus to $1550 \mathrm{~ms}$ post-stimulus, all epochs were aligned to a baseline from -200 to $0 \mathrm{~ms}$ preceding the stimulus. Epochs were low-pass filtered at $15 \mathrm{~Hz}(24 \mathrm{~dB} / \mathrm{Oct})$ and epochs containing artifacts or horizontal eye movements exceeding $\pm 120 \mu \mathrm{V}$ were rejected from the database. Vertical EOG artifacts were subtracted from the data by applying an eye-movement correction algorithm (Semlitsch, Anderer, Schuster, \& Presslich, 1986). Next, average ERPs were computed for each participant separately for old and new conditions and for pre- and post-training sessions.

\section{Statistical analyses}

\section{Computerised memory recognition (Old/New) task}

Memory recognition performance was studied by computing percentage correct responses (correctly accepted old items and correctly rejected new 
items) and reaction time (RT) on these trials. To verify the success of the task manipulation, first old/new main effects were tested for accuracy and RT measures by repeated measures ANOVA.

Subsequently, two planned $2 \times 2$ repeated measures ANOVAs including the factor Training Group (MST vs. PLA or MST vs. APM) and Session (pre- vs. post-assessment) were performed to compare the effects of memory strategy training on recognition performance with effects in both active control trainings. To examine the specificity of training effects for the Old/New Recognition task, effects of the training on performance during the Animate/Inanimate task (in the study phase) were also investigated by performing a Stimulus Type (animate/inanimate) $\times$ Session (pre-, post-) $\times$ Training group (PLA, APM, MST) repeated measures ANOVA for percentage correct detections and accompanying response times. A two-tailed significance level of $p<.05$ was adopted for these tests.

\section{Neuropsychological tests and symptom scores}

Mixed repeated measures ANOVAs including a within factor Session (pre-, post-training) and a between factor Training group (MST, APM, PLA) were performed for the following dependent measures: (1) number of missed targets and total time spent on the task for the VAT and Bells task, (2) standardised memory span measures on Number Recall and Word Order tests, (3) parent ratings on a DSM-IV-based ADHD symptom scale (AVL; Scholte et al., 2001; for further explanation of this questionnaire see above) , and (4) teacher (TRF) and parent (CBCL) externalising and internalising behaviour problem scores (see also above). For all tests a two-tailed significance level of $p<.05$ was adopted. Significant Session $\times$ Training group interactions were followed up by two planned contrasts in which training differences between MST and the two control trainings were tested.

\section{ERP analyses}

To determine regions of interest (ROIs) for investigating training effects on ERP activity, first, strongest old/new effects across groups were identified by testing for main old/new effects by performing ANOVA analyses in $50 \mathrm{~ms}$ time windows from 200-1000 ms post-stimulus at the separate leads. To prevent type I errors, such main old/new effects in the ERP were only accepted at the highly conservative significance level of $p<.00001$. Subsequently, to evaluate training effects, planned Session (pre- and post-session) $\times$ Training group (PLA, APM, MST) contrasts for old items were performed in the time windows and electrodes at which the strongest old/new effects on the frontocentral negativity and parietal positivity were present (see Figure 2). For the electrodes at which old/new effects were found in similar time windows, one ANOVA was performed including an electrode factor. This yielded 13 separate 
ROIs at which training effects were tested; effects were corrected for multiple testing (see results section below).

\section{RESULTS}

\section{Computerised episodic memory recognition task}

\section{Behavioural effects}

One-way ANOVA showed that there were no significant group differences in pre-training accuracy or RT scores (\% hits_old: $p=.31, \%$ hits_new: $p=$ .72 , RT_old: $p=.32$, RT_new: $p=.97)$.

Old/new effects. Analyses of percentage correct detections of old and new items and accompanying response times are presented in Table 2. First, significant old/new main effects (for correctly detected old items and correctly rejected new items) were found for accuracy, $F(1,31)=9.2, p=$ $.005, \eta_{p}^{2}=0.23$, and RT, $F(1,31)=12.0, p=.002, \eta_{p}^{2}=0.28$. Participants had higher accuracy (new $81 \%$ vs. old $75 \%$ ) and were somewhat slower (new $762 \mathrm{~ms}$ vs. old $752 \mathrm{~ms}$ ) to reject new items than to correctly identify old items.

Training effects on task performance in Old/New task. To test the hypothesis as formulated at the end of the introduction, two separate planned contrasts for new and old items were performed. For new items, as expected, no main effects of Training group or Session $\times$ Training group interactions were found for percentage of hits or RT. For old item RT, no significant main Training group or Session $\times$ Training group effects were found.

For old item recognition accuracy however, the Session $(2) \times$ Training group (3) interaction was near-significant, $F(2,31)=3.25, p=.052$, $\eta_{p}^{2}=$ 0.17. Further testing of this interaction showed that significant Session $\times$ Training group effects were present between MST and PLA groups, $F(1$, $21)=5.2, p=.034, \eta_{p}^{2}=0.20$, but not between the MST and APM groups, $F(1,21)=.008, p=.930, \eta_{p}^{2}=0.00$. There was a significant increase in percentage of correctly recognised old items from pre- to posttraining sessions after MST, $t(11)=-2.95, p=.025$, and a borderline significant effect after APM, $t(10)=-2.21, p=.052$, but no effect after placebo training, $t(10)=.78, p=.45$ (see Table 2 ). Inspection of the data showed that, respectively, $82 \%$ (9 out of 11) and $83 \%$ (10 out of 12) of the children from the APM and MST training groups had improved memory performance after training, whereas only $27 \%$ (3 out of 11) improved after placebo training. 


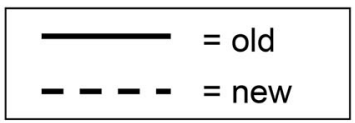

\section{Frontal negativity}

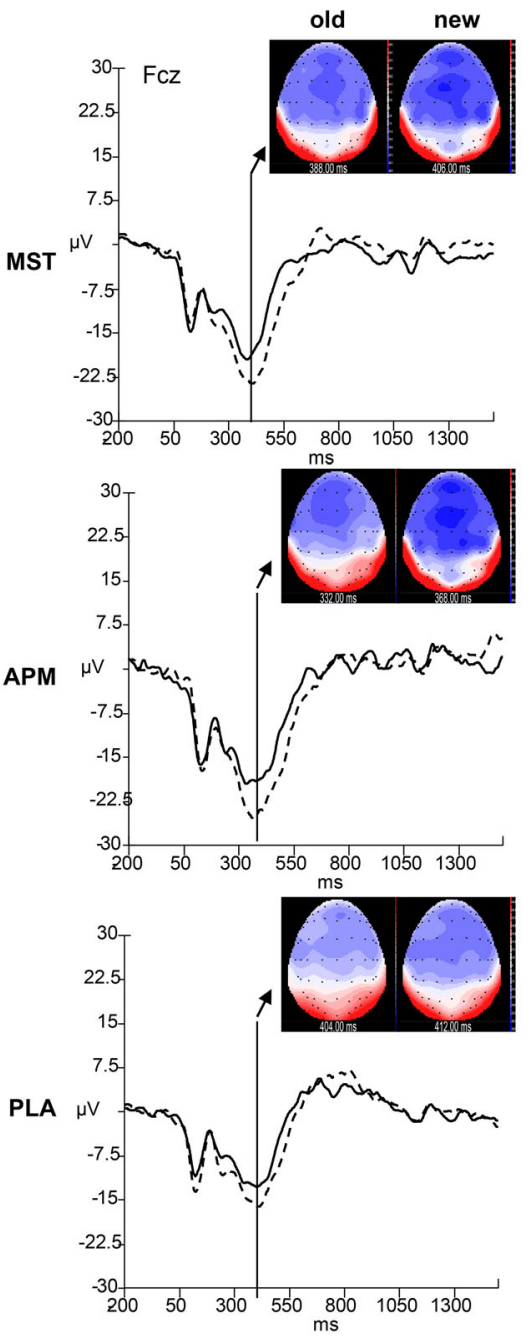

Parietal positivity

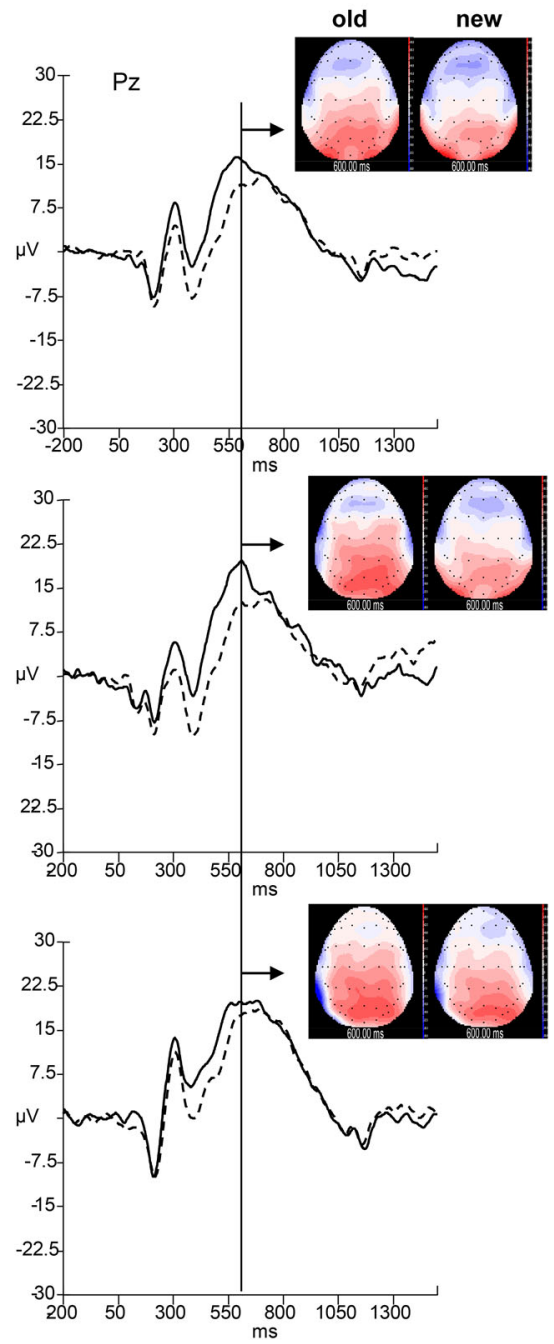

Figure 2. Event-related brain potentials (ERPs) at $\mathrm{FCz}$ (left row) and $\mathrm{Pz}$ (right row) electrodes for old and new items in memory strategy (MST), attention-perceptual-motor (APM) and placebo (PLA) groups, averaged over pre- and post-training sessions. The left row shows the frontal negativity (new $>$ old) and accompanying topographic maps at maximum negative amplitude across all electrodes. The right row shows the parietal positivity (old $>$ new) and accompanying topographic maps at $600 \mathrm{~ms}$ in all groups. 
TABLE 2

Task performance in MST, APM and PLA training groups before (pre) and after (post) the training in the Old/New recognition memory task during the test phase (memory performance) and in the animate/inanimate discrimination task during the study phase (as control for specificity of training effects on memory performance) and in the four paperand-pencil neuropsychological attention (VAT and Bell) and memory span (Number recall and Word Order) tests

\begin{tabular}{|c|c|c|c|c|c|c|}
\hline \multirow[b]{2}{*}{ Training } & \multicolumn{2}{|c|}{$M S T$} & \multicolumn{2}{|c|}{$A P M$} & \multicolumn{2}{|c|}{ PLA } \\
\hline & Pre & Post & Pre & Post & Pre & Post \\
\hline \multicolumn{7}{|c|}{ Test phase memory recognition } \\
\hline Percent hits old items & $74(11)$ & $82(13)$ & $70(17)$ & $83(12)$ & $79(9)$ & $76(8)$ \\
\hline Percent hits new items & $82(17)$ & $83(19)$ & $78(14)$ & $83(12)$ & $84(18)$ & $76(8)$ \\
\hline RT old items (ms) & $792(100)$ & $732(91)$ & $754(32)$ & $710(57)$ & $753(54)$ & 768 (111) \\
\hline RT new items (ms) & $792(158)$ & $768(121)$ & $790(82)$ & $761(79)$ & $780(127)$ & $828(128)$ \\
\hline \multicolumn{7}{|c|}{ Study phase discrimination task } \\
\hline Percent hits animate & $92(9)$ & $96(6)$ & $91(6)$ & $93(6)$ & $91(7)$ & $93(6)$ \\
\hline Percent hits inanimate & $87(15)$ & $92(13)$ & $87(7)$ & $95(8)$ & $89(9)$ & $96(6)$ \\
\hline RT animate (ms) & 703 (149) & $640(87)$ & $671(59)$ & $625(59)$ & $676(87)$ & $672(85)$ \\
\hline RT inanimate (ms) & $683(153)$ & $655(90)$ & $687(83)$ & $664(77)$ & $703(67)$ & $629(105)$ \\
\hline \multicolumn{7}{|l|}{ Visual attention tests } \\
\hline Bell-time (s) & $161(60)$ & $130(63)$ & $144(79)$ & $136(76)$ & $137(37)$ & $149(44)$ \\
\hline Bell-no. of misses & $7(7)$ & $3(3)$ & $7(8)$ & $4(4)$ & $3(3)$ & $4(4)$ \\
\hline VAT-time (s) & $44(16)$ & $34(8)$ & $40(17)$ & $38(14)$ & $39(5)$ & $46(14)$ \\
\hline \multicolumn{7}{|l|}{ Memory span tests } \\
\hline Number Recall & $7.7(2.5)$ & $8.3(1.6)$ & $6.6(2.5)$ & $7.6(2.0)$ & $7.3(2.5)$ & $8.3(2.5)$ \\
\hline Word Order & $7.2(3.7)$ & $9.3(2.7)$ & $8.1(2.2)$ & $8.0(2.7)$ & $7.3(2.5)$ & $8.4(2.2)$ \\
\hline
\end{tabular}

MST $=$ memory strategy, APM $=$ attention-perceptual-motor, $\mathrm{PLA}=$ placebo, $\mathrm{RT}=$ reaction time in milliseconds (ms), VAT $=$ Visual Attention Task. $S D$ s in parentheses.

Further testing of a significant one-way ANOVA effect for IQ showed that the MST and PLA groups did not differ in IQ, MST-PLA: $t(21)=1.2, p=$ .23. The mean IQ in the APM training group was however lower than mean IQ in PLA group, APM-PLA: $t(20)=2.8, p=.01$, and MST group, APM-MST: $t(21)=-2.6, p=.02$. Therefore, all the above analyses were repeated with IQ as a covariate, but this did not significantly change the above-reported effects.

Animate/inanimate discrimination (study phase). The 2 (Condition: animate vs. inanimate) $\times 2$ (Session: pre vs. post) $\times 3$ (Training group: MST, APM, PLA) mixed repeated measures ANOVA only revealed significant or nearly significant main Session effects for percent hits and RT, $F(1$, $31)=11.8, p=.002, \eta_{p}^{2}=0.28$ and $F(1,31)=3.8, p=.06, \eta_{p}^{2}=0.11$, but no Session $\times$ Training group or Condition $\times$ Session $\times$ Training group interactions. The main effects indicate that all participants made more 
accurate and faster animate/inanimate discriminations during the study phase in the post-session, compared to the pre-session. This effect was however present in all groups and was thus independent of the type of training the children received (see Table 2).

\section{ERP effects}

Old/new recognition effects. As explained above, during the computerised memory recognition task, ERPs were measured to investigate training effects on brain measures related to memory recollection (e.g., the P600). First, the ERPs in all groups showed a clear fronto-centrally distributed negativity that was larger to new than old items (see Figure 2). This old/new effect was present around midline fronto-central (F1, FC1, FCz, FC2, C3, C1, Cz, C2) and right-hemisphere fronto-central electrodes (F8, F6, FT8, FC6, FC4,T8, C6, C4) in different time windows between 250-600 ms. Second, a clear posteriorly distributed positivity was present in all groups and, as expected, was significantly enhanced to correctly recognised old items compared to correctly rejected new items in all groups (see Figure 2). This old/ new effect on the positive component had a broad distribution across posterior (temporal-parietal, centro-parietal, parietal, and occipital) electrodes and occurred between $300-650 \mathrm{~ms}$.

Training effect old items. Session $\times$ Training group effects on ERPs were investigated for correctly recognised old items in predetermined time windows and specific regions of interest (ROIs) in which old/new effects in the three groups were strongest (see previous paragraph). More specificly, for the frontal negativity, five separate ANOVAs were performed for left frontal (F1) from 450-550 ms; right frontal (F6 and F8) from 450-500 ms; fronto-central (FC1, FCz, FC2, FC4, FC6, FT8) from 450-550 ms, and right central (C2, C4, C6, T8 from 450-600 ms; C4, C6, T8 from 250$400 \mathrm{~ms}$ ) ROIs. For the parietal positivity, eight separate ANOVAs were performed for the following ROIs and time-windows: left temporal-parietal (TP7, CP5, CP3), from 350-450 ms and 450-650 ms (only CP5, CP3); centro-parietal (CP1, CPz, CP2, CP4) from 350-600 ms; right temporal-parietal (CP6, TP8) from 400-600 ms; left parietal (P7, P5) from 500-600 ms; medial parietal (P1, P3, Pz, P2, P4) from 350-600 ms; right parietal-occipital (P8, PO8) from 750-900 ms, and medial parietal-occipital (PO3, PO4, Oz, O2) from 450-550 ms. Only Session $\times$ Training group effects that reached a two-tailed significance level of $p<.05$ corrected for multiple testing (the 13 ANOVA tests) were adopted. For the parietal positivity, this yielded a significant Session $\times$ Training group interaction at left parietal leads (P5 and P7) in the time window from 500-600 ms, Session $\times$ Training-group: $F(2,31)$ $=7.9, p=.002$; corrected $p$-value $=.026$. Since there was no interaction 
with Leads $(\mathrm{S} \times \mathrm{TG} \times \mathrm{L}: p=.44)$, amplitudes were averaged over P7 and P5 electrodes for further post-hoc testing. A significant Session $\times$ Training group effect was present between MST and PLA groups, $F(1,21)=11.6$, $p=.003, \eta_{p}^{2}=0.36$, but not between MST and APM groups, $F(1,21)=$ $.071, p=.793, \eta_{p}^{2}=0.00$. Paired $t$-tests showed significant pre- to post-training increases in left parietal positivity after MST $(p=.05)$ and APM $(p=$ $.034)$ training but a significant decrease after placebo training $(p=.037$; see Figure 3). Covariance analyses showed that these effects remained significant after including IQ as a covariate. No other Session $\times$ Training-group effects (at $p$ level corrected for 13 multiple ANOVA tests) were found for the frontal negativity or the parietal positivity at the other ROIs and predefined time windows.

Correlation between old item recognition improvement and left P600 increase. To investigate relations between training effects on recognition performance and memory-related brain activity across all participants, difference scores (post- minus pre-training) were computed for the percentage of correctly recognised old items and the amplitude of the positivity between 500-600 ms averaged across P5 and P7 electrodes. There was a positive correlation between the post-pre difference in old item recognition and the post-pre amplitude difference, $r(34)=.40, p=.017$, indicating that participants with the largest left parietal amplitude increase after training had the largest old item recognition increase from pre- to post-session (see Figure 4).

\section{Neuropsychological tests}

\section{Visual attention tests (Bells Test and VAT)}

The visual attention data from one participant in the placebo group could not be used because of problems with the stop-watch. Time spent on task (Bells and VAT) and number of misses (only Bells task) during pre- and post-sessions are presented in Table 2. One-way ANOVA analysis showed no significant differences between the three groups during pre-test (Bell-time: $p=.65$, Bell-miss: $p=.19$, VAT-time: $p=.75)$. Significant Session $\times$ Training group interaction effects were found for the total time spent on task for both the Bells Test, $F(2,31)=3.3, p=.05, \eta_{p}^{2}=0.18$, and the VAT, $F(2,30)=5.0, p=.01, \eta_{p}^{2}=0.25$. Follow-up tests showed significant differences in training effects between the MST and PLA groups, Bells Test: $F(1,20)=4.9, p=.04, \eta_{p}^{2}=0.20$ and VAT: $F(1,20)=8.6, p=.008, \eta_{p}^{2}$ $=0.30$, but not between MST and APM groups, Bells Test: $F(1,21)=1.9, p$ $=.19, \eta_{p}^{2}=0.08$ and VAT: $F(1,21)=2.2, p=.15, \eta_{p}^{2}=0.10$. Paired $t$ tests revealed a significant decrease in time spent on the task after MST training $(p<.05)$, but not after APM or PLA. 


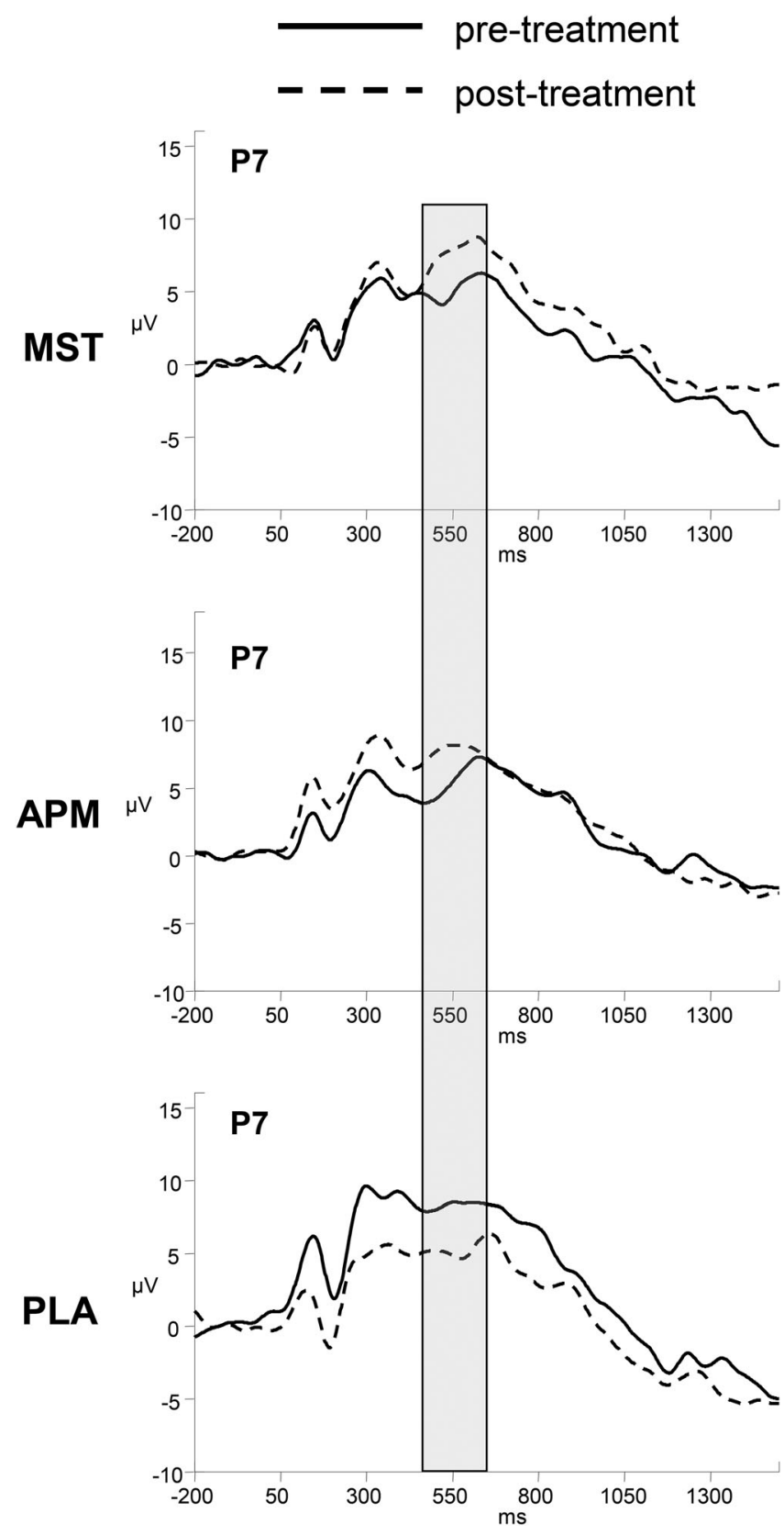

Figure 3. Event-related brain responses accompanying correct recognition of old items before (pre) and after (post) training at the left parietal electrode P7 in memory strategy (MST), attentionperceptual-motor (APM) and placebo (PLA) training groups. The bar indicates the time-window (500-600 ms) in which the parietal positivity was significantly enhanced after MST and APM training, but reduced after PLA training. 


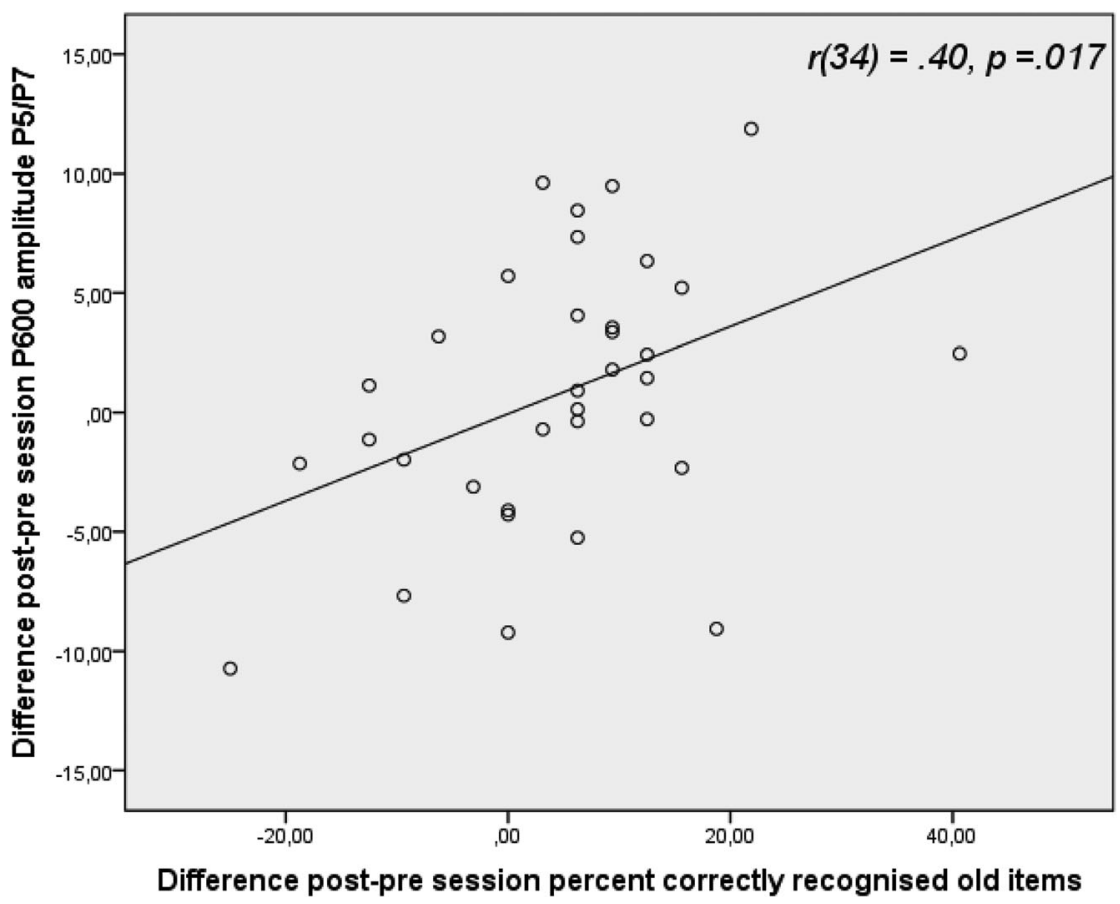

Figure 4. Correlation between training-induced improvements (post- minus pre-training scores) in old item recognition accuracy (X-axis) and old-item ERP activity from 500-600 ms averaged over P5 and P7 electrodes (Y-axis).

For the number of missed targets, a significant Session $\times$ Training group interaction, $F(2,30)=3.7, p=.036, \eta_{p}^{2}=0.20$, was found for the Bells Test. Follow-up tests showed a significant difference in training effects between MST and PLA groups, $F(1,20)=6.6, p=.02, \eta_{p}^{2}=0.25$, and MST and APM groups, $F(1,21)=5.1, p=.03, \eta_{p}^{2}=0.19$; there was a decrease in misses in the PLA $(p=.06)$ and APM $(p=.09)$ groups from pre- to post-training, but there was no pre to post difference in misses in the MST group $(p=.25)$. Including IQ as a covariate did not change the results of the above analyses in a significant ways. Because almost no misses were made in the VAT task, no miss analysis could be executed for this task.

\section{Standardised memory span tests}

One-way ANOVA analyses showed no significant group differences in pre-test standardised number recall or word order standardised span scores ( $p=.63$ and $p=.72$, respectively). 
Number recall (digit-recall forward: verbal STM): The ANOVA analyses only yielded a significant main effect of Session, $F(1,31)=4.7, p=.04, \eta_{p}^{2}$ $=0.13$, indicating that, irrespective of type of training, number recall performance increased from pre- to post-session. The Session $\times$ Training group interaction was not significant, $F(2,13)=.127, p=.88, \eta_{p}^{2}=0.01$. After including IQ as covariate the main Session effect was no longer significant $(p=.13)$. For mean scores see Table 2 .

Word order span: The ANOVA analysis showed a main effect of Session, $F(1,31)=6.9, p=.013, \eta_{p}^{2}=0.18$, and a marginally significant Session $\times$ Training group interaction, $F(2,31)=2.7, p=.085, \eta_{p}^{2}=0.15$. Further testing of this interaction showed that a significant Session $\times$ Training group effect was present between MST and APM groups, $F(1,21)=4.6, p$ $=.04, \eta_{p}^{2}=0.18$, but not between the MST and PLA groups, $F(1,21)=1.9$, $p=.19, \eta_{p}^{2}=.08$. There was a significant increase in standardised scores on the word order memory test from pre- to post-training sessions after MST, $t(11)=-2.4, p=.035$, after PLA, $t(10)=2.3, p=.045$, but no effect after APM training, $t(10)=0.16, p=.88$ (see Table 2). After including IQ as a covariate, the ANOVA main and interaction effects were however no longer significant, $p=.73$ and $p=.26$, respectively.

\section{ADHD symptom ratings}

Since the majority of parents unfortunately did not return or only partly filled in the post-session questionnaires this analysis is based on very small groups $(n=5, n=6$ and $n=9$ in MST, APM and PLA groups, respectively). The ADHD symptom scale analysis showed no significant main Session effects but significant Session $\times$ Training group interactions were found for inattention symptoms, $F(2,17)=4.4, p=.029, \eta_{p}^{2}=$ 0.34 , and impulsivity symptoms, $F(2,17)=4.5, p=.027, \eta_{p}^{2}=0.35$, and a marginally significant interaction effect for hyperactivity, $F(2,17)$ $=3.0, p=.08, \eta_{p}^{2}=0.26$. Further paired $t$-tests showed significant training effects only after memory strategy training (inattention: $p=.02$, hyperactivity: $p=.04$, impulsivity: $p=.05$ ); as indicated by parents, mean inattentive symptoms reduced after MST from 15.0 to 10.0, hyperactivity symptoms from 19.8 to 13.8 , and impulsive symptoms from 18.0 to 12.4 .

The CBCL analysis was based on returned questionnaires of $n=8, n=8$, $n=10$ and the TRF on $n=11, n=11, n=10$ in MST, APM and PLA groups, respectively. For CBCL and TRF externalising and internalising $T$ scores there was a significant main Session effect only for CBCL externalising behaviour scores, CBCL-ext: Session $F(1,23)=15.9, p=.001, \eta_{p}^{2}=$ 0.40 ; indicating that, according to parents, externalising behaviour was reduced from pre- to post-session, but this was irrespective of the training 
group that children were in. No effects were found for CBCL and TRF internalising scores or TRF externalising scores.

\section{DISCUSSION}

The main aim of the present preliminary study was to investigate the effects of explicit memory strategy training on episodic memory recognition performance and accompanying brain activity (ERPs) in children with ADHD. Additionally, training effects on ADHD symptom ratings and on neuropsychological visual attention and short-term/working memory span tests were investigated. The hypotheses were partly confirmed; compared to placebo training (playing board games) memory strategy training did significantly enhance ADHD children's memory performance (higher correct old item recognition). The absence of training effects on new item recognition accuracy/ speed or on general task performance (animate discrimination task during study) confirms the selectivity of memory strategy training effects for only earlier learned information. There was no effect on old item recognition speed, but note that finding effects only on accuracy and not speed measures is common in the ADHD literature due to the key cognitive disorder of high reaction time variability. The training-related increase in old item memory recollection was accompanied by, and even positively correlated with, increased left parietal P600 activity. Similar enhancements of old item recognition performance (although borderline significant) and left parietal P600 enhancement were however seen after attention-perceptual-motor training. Compared to both other trainings, memory strategy training did have specific positive effects on ADHD symptoms as rated by parents, but this latter effect has to be interpreted with care considering the low number of returned posttraining questionnaires. These effects will be discussed in more detail below.

\section{Training effects on episodic memory recollection and associated ERP activity}

The increase in memory performance (old item recognition) after attentionperceptual-motor and memory strategy training was accompanied by enhanced left parietal ERP positivity, 500-600 ms after presentation of old items during the recognition test phase of the task. This complies with previous ERP and fMRI studies also revealing an association between enhanced left parietal activity and successful recognition/recollection of old items from episodic memory (Donaldson, Petersen, Ollinger, \& Buckner, 2001; Eldridge, Knowlton, Furmanski, Bookheimer, \& Engel, 2000; Henson et al., 2005). A prior ERP study, using a similar paradigm, has reported higher left parietal P600 responses during recollection of information that was previously encoded more deeply (Donaldson \& Rugg, 1998). Similarly, fMRI research 
has shown higher left parietal activation during successful recollection when there was a higher overlap in context in which items were studied and recollected (Henson et al., 2005). Furthermore, prior findings have indicated that the magnitude of the left parietal ERP effect varied with the amount of information recollected (Rugg \& Wilding, 2000; Vilberg, Moosavi, \& Rugg, 2006; Wilding, 2000). Such a link between left-parietal (and left-fusiform) cortex activation and amount of remembered information was also suggested in an fMRI study (Vilberg \& Rugg, 2007) and led to the conclusion that these regions support the representation of earlier stored information. Regarding this evidence, and since in-depth processing of old items in the present study was accomplished by performing a semantic decision task during the study phase (Eldridge et al., 2000), the enhanced parietal activity accompanying improved old item identification after training is suggested to signal improved recollection processes, i.e., better or enhanced retrieval of earlier stored information. Such a relation between the success of old item recognition and left parietal activity was in the present study supported by a significant .40 correlation between pre- and post-training differences in the percentage of correct old item recognition and the left parietal amplitude increase at P5 and P7 electrodes. This correlation indicates that participants with the largest old item recognition increase after training also had the largest left parietal amplitude increase. Similarly, the decrease in left parietal activation after the placebo training might be interpreted as a reduction in the amount of information recollected during the post-session; this would correspond with the small reduction in the percentage of correctly recognised old items in the post-session in this group, although this was not statistically significant.

An interesting question is how the memory strategy and attention-perceptual-motor trainings might have improved recollection performance. Regarding the evidence of enhanced left parietal recollection-related activity when items were more deeply encoded, we tentatively suggest that both strategy trainings established their positive memory effects by improving the encoding of information. Memory strategy training might have improved encoding by more efficient application of learned memory encoding strategies and attention-perceptual-motor training by enhancing attentional focus and allocation during study. Such attention effects would be congruent with suggestions by Kaplan, Dewey, Crawford, and Fisher (1998) that impaired memory performance in children with ADHD is primarily due to attention problems during the initial learning (encoding) phase of a task. Also, a recent meta-analysis study led to the conclusion that in adult ADHD verbal long-term memory deficits were related to learning deficits during memory encoding and not to memory retrieval problems (Skodzik, Holling, \& Pedersen, 2013). Such conclusions, however, remain speculative at this stage and future work should also study effects of memory strategy (and attention) training on ERP activity 
in the encoding phase of a memory task. A recent study in healthy adults has provided evidence for differences in ERP responses during application of a simple rehearsal versus an elaborate semantic grouping strategy in the encoding phase of a memory task (Schleepen, Markus, \& Jonkman, 2014).

\section{Training effects on attention, short-term/working memory performance}

Compared to placebo training the memory strategy training also improved focused attention as shown by faster target detection speed (without accuracy decrements) in both neuropsychological paper-and-pencil attention tests (VAT and Bells Cancellation). Attention-perceptual-motor training showed similar positive attention effects which is not surprising because of the fact that visual attention exercises similar to the VAT and Bells Test were part of the latter training. Whereas the present study cannot identify the mechanisms through which memory strategy training might have established these attention effects, on the basis of prior work it might be speculated that such effects are reached by training-induced increases in working memory capacity, leading to more top-down control and better focused attention. This is supported by studies showing a slowing of target detection times in visual attention tasks similar to the presently used tasks (although computerised) when a concurrent spatial working memory load was imposed that overlapped with the spatial attention requirements of the search task, thereby decreasing working memory capacity and top-down executive control (Awh, Vogel, \& Oh, 2006; Oh \& Kim, 2004; Woodman \& Luck, 2004). Further support comes from a study showing that participants with high working memory capacity were shown to be faster in identifying target stimuli in a visual search task, but only in conditions that required top-down attention control (Poole \& Kane, 2009). Several studies have indeed reported increases in working memory capacity after training of elaborative memory strategies in adults (Carretti, Borella, \& De Beni, 2007; McNamara \& Scott, 2001; Turley-Ames \& Whitfield, 2003) and typically developing children (St Clair-Thompson et al., 2010).

Indeed, the results do provide some evidence for enhanced working memory capacity (but not short-term memory capacity) in ADHD children after memory strategy training, as shown by a statistically significant twoitem increase in the word order span score. In the word order test (K-ABC; Kaufman \& Kaufman, 1983) children had to reproduce a verbally presented word list in the correct serial order by pointing at pictures of objects representing the words from the list that are presented amongst distractors. Whereas this is not the most commonly used working memory span test in the developmental literature, it has been regarded as an "executive working memory test", because of its combined demands on both verbal and visuo-spatial 
processing, and the suppression of interference from distractor items (see Dehn, 2008, pp. 187, 189-190). It has, however, to be noted that whereas there was no word order span increase after attention training, the children in the placebo group did show a word order increase from pre- to post-test. This increase in the PLA group was smaller than in the MST group but not statistically so. This result needs careful interpretation and needs to be replicated with larger groups and with inclusion of multiple, more commonly used, standardised verbal and visuo-spatial working memory tests, such as listening recall or spatial span (Alloway, 2007). The fact that, compared to PLA, MST only selectively improved working memory capacity and not short-term memory (STM) capacity (measured by forward number recall), is congruent with earlier findings that only working memory (and not STM) capacity influenced or mediated the successful use of the elaborative strategy semantic grouping in typically developing children (Lehmann \& Hasselhorn, 2007; Schleepen \& Jonkman, 2012). It might be that since elaborative memory strategies pose such high demands on working memory capacity, their repeated application during training might lead to a more effective use of such capacity, possibly explaining MST training-induced increases in performance especially on working memory span tasks.

\section{Training effects on ADHD symptoms}

Parents reported an improvement in inattention, impulsivity and hyperactivity symptoms after the memory strategy training, whereas such effects were not reported for the attention-perceptual-motor or placebo trainings. A similar reduction in inattention symptoms was reported by parents after computerised working memory training (Klingberg et al., 2005). Although the mechanism through which MST improves such seemingly different ADHD symptoms is not clear, it might be that inattentive and hyperactive behaviour share executive resources that are enhanced through MST. Interestingly, a recent study showed that involuntary lapses of attention (seen frequently in ADHD) were due to a loss of executive control that did not only have detrimental effects on cognitive performance but also increased motor restlessness (e.g., fidgeting behaviour; Seli et al., 2014). The present results suggest that memory strategy training might have the potential for far transfer to behaviour, but replication with larger samples is needed since very few post-training questionnaires were returned by the parents. Parents and teachers also reported a decrease in externalising behaviour after memory training, but this decrease was also reported after attention-perceptual-motor- and placebo trainings. No effects were found on internalising behaviour.

It is important to note that IQ differences could not account for the memory enhancing effects of memory strategy training on task performance or ERPs, since MST and placebo groups did not differ in IQ, whereas there were IQ 
differences between APM and PLA groups. Further, since parents and teachers did not indicate any pre-training differences in internalising (anxiety and affective disorders) or externalising (oppositional defiant disorder, conduct disorder) co-morbidity or attention or thinking problems between the three groups, these could also not account for the reported training effects. Finally, the current data showed that both cognitive trainings had positive effects that were additive to medication, since the majority of the children used their normal dose of medication during the entire study. There were a few children that did not take medication and this number varied somewhat between training groups. Exclusion of these children did not change results in any way, suggesting that the positive training effects might at least partly be independent of medication use, but this needs further investigation with larger groups of medication-free children.

\section{Limitations}

Whereas the present results are promising since they suggest a specific effect of training in which children are acquainted with elaborative memory or attention strategies (as opposed to computer training) on episodic recollection performance and associated ERP activity, there are limitations that have to be taken into account. First, further research is needed to explore the long-term effects of the present training. Earlier fMRI research showed neural gain after two weeks of computerised working memory training that however diminished again after four weeks of training (Hempel et al., 2004). Second, future studies should further elucidate the specific strategies and underlying brain mechanisms through which the present effects might have been achieved by also studying brain activity during encoding. Also, future studies should include a broader array of episodic memory tasks and more commonly used (computerised) attention and working memory tasks, as well as measures of academic performance. If such long-term effects and far transfer to academic performance can be established in future studies, memory strategy trainings seem highly promising for educational practice because they are much easier to integrate in the classroom setting than currently used computerised working memory training. The potential importance of memory training, and especially training of the strategic component of memory, in primary school has recently also been acknowledged by others (Sander, Werkle-Bergner, Gerjets, Shing, \& Lindenberger, 2012).

\section{REFERENCES}

Achenbach, T. M., \& Rescorla, L. A. (2001). Manual for the ASEBA school-age forms and profiles. Burlington: University of Vermont, Research Center for Children, Youth and Families. 
Alloway, T. P. (2007). Automated working memory assessment. London, England: Pearson Assessment.

American Psychiatric Association (2013). Diagnostic and statistical manual of mental disorders (5th ed.). Washington, DC: Author.

August, G. J. (1987). Production deficiencies in free recall: A comparison of hyperactive, learning-disabled, and normal children. Journal of Abnormal Child Psychology, 15, 429-440.

Awh, E., Vogel, E. K., \& Oh, S. H. (2006). Interactions between attention and working memory. Neuroscience, 139, 201-208.

Biederman, J., Monuteaux, M. C., Doyle, A. E., Seidman, L. J., Wilens, T. E., Ferrero, F. ... Faraone, S. V. (2004). Impact of executive function deficits and attention-deficit/hyperactivity disorder (ADHD) on academic outcomes in children. Journal of Consulting and Clinical Psychology, 72, 757-766.

Brehmer, Y., Li, S-C., Müller, V., Oertzen, T. v., \& Lindenberger, U. (2007). Memory plasticity across the life span: Uncovering children's latent potential. Developmental Psychology, 43, $465-478$.

Bunge, S. A., \& Wright, S. B. (2007). Neurodevelopmental changes in working memory and cognitive control. Current Opinion in Neurobiology, 17, 243-250.

Carretti, B., Borella, E., \& De Beni, R. (2007). Does strategic memory training improve the working memory performance of younger and older adults? Experimental Psychology, 54, 311-320.

Colom, R. Quiroga, M. A., Shih, P. C., Martinez, K., Burgaleta, M., Martinez-Molina, A., ... Ramirez, I. (2010). Improvement in working memory is not related to increased intelligence scores. Intelligence, 38, 497-505.

Cornoldi, C., Barbieri, A., Gaiani, C., \& Zocchi, S. (1999). Strategic memory deficit in attention deficit disorder with hyperactivity participants: The role of executive processes. Developmental Neuropsychology, 15, 53-71.

Craik, F. I. M., \& Lockhart, R. S. (1972). Levels of processing: A framework for memory research. Journal of Verbal Learning and Verbal Behavior, 11, 671-684.

Cycowicz, Y. M. (2000). Memory development and event-related brain potentials in children. Biological Psychology, 54, 145-174.

Cycowicz, Y. M., Friedman, D., Rothstein, M., \& Snodgrass, J. G. (1997). Picture naming by young children: Norms for name agreement, familiarity, and visual complexity. Journal of Experimental Child Psychology, 65, 171-237.

Cycowicz, Y. M., Friedman, D., Snodgrass, J. G., \& Duff, M. (2001). Recognition and source memory for pictures in children and adults. Neuropsychologia, 39, 255-267.

Dehn, M. J. (2008). Working memory and academic learning: Assessment and Intervention. Hoboken, NJ: John Wiley \& Sons.

Donaldson, D. I., Petersen, S. E., Ollinger, J. M., \& Buckner, R. L. (2001). Dissociating state and item components of recognition memory using fMRI. Neuroimage, 13, 129-142.

Donaldson, D. I., \& Rugg, M. D. (1998). Recognition memory for new associations: Electrophysiological evidence for the role of recollection. Neuropsychologia, 36, 377-395.

Dopfner, M., Schmeck, K., Poustka, F., Berner, W., Lehmkuhl, G., \& Verhulst, F. (1996). Behavioral symptoms of children and adolescents in Germany, The Netherlands and USA. A cross-cultural study with the Child Behavior Checklist. Nervenarzt, 67, 960-967.

Dunning, D. L., Holmes, J., \& Gathercole, S. E. (2013). Does working memory training lead to generalized improvements in children with low working memory capacity. A randomized controlled trial. Developmental Science, 16, 915-925.

Egeland, J., Johansen, S. N., \& Ueland, T. (2010). Do low-effort learning strategies mediate impaired memory in ADHD? Journal of Learning Disabilities, 43, 430-440.

Eldridge, L. L., Knowlton, B. J., Furmanski, C. S., Bookheimer, S. Y., \& Engel, S. A. (2000). Remembering episodes: A selective role for the hippocampus during retrieval. Nature Neuroscience, 3, 1149-1152. 
Ericsson, K. A., \& Kintsch, W. (1995). Long-term working memory. Psychological Reviews, 102, 211-245.

Frazier, T. W., Youngstrom, E. A., Glutting, J. J., \& Watkins, M. W. (2007). ADHD and achievement: Meta-analysis of the child, adolescent and adult literatures and a concomitant study with college students. Journal of Learning Disabilities, 40, 49-65.

Gauthier, L., Dehaut, F., \& Joanette, Y. (2004). The bells test: A quantative and qualitative test for visual neglect. In M. D. Lezak, D. B. Howeison, \& D. W. Loring (Eds.), Neuropsychological assessment (pp. 380-381). Oxford: University press.

Hempel, A., Giesel, F. L., Garcia Caraballo, N. M., Amann, M., Meyer, H., Wustenberg, T. .. . Schröder, J. (2004). Plasticity of cortical activation related to working memory during training. American Journal of Psychiatry, 161, 745-747.

Henson, R. N., Hornberger, M., \& Rugg, M. D. (2005). Further dissociating the processes involved in recognition memory: An FMRI study. Journal of Cognitive Neuroscience, 17, $1058-1073$.

Johnson, J., \& Reid, R. (2011). Overcoming executive function deficits with students with ADHD. Theory into Practice, 50, 61-67.

Kaplan, B. J., Dewey, D., Crawford, S. G., \& Fisher, G. C. (1998). Deficits in long-term memory are not chracteristic of ADHD. Journal of Clinical and Experimental Neuropsychology (Neuropsychology, Development and Cognition: Section A), 20, 518-528.

Karatekin, C. (2004). A test of the integrity of the components of Baddeley's model of working memory in attention-deficit/hyperactivity disorder (ADHD). Journal of Child Psychology and Psychiatry, 45, 912-926.

Kaufman, A. S., \& Kaufman, N. L. (1983). Kaufman Assessment Battery for Children (K-ABC). Minnesota, USA: American Guidance Service.

Kaufman, A. S., Lichtenberger, E. O., Fletcher-Janzen, E., \& Kaufman, N. L. (2005). Essentials of KABC-II assessment. Hoboken: John Wiley \& Sons.

Kemp, S. L. \& Korkman, M. (2010). Essentials op nepsy-ii assessment. Hoboken: Wiley.

Klingberg, T., Fernell, E., Olesen, P. J., Johnson, M., Gustafsson, P., Dahlstrom, K., ... Westerberg, H. (2005). Computerized training of working memory in children with ADHD-a randomized, controlled trial. Journal of the American Academy of Child and Adolescent Psychiatry, 44, 177-186.

Korkman, M., Kirk, U., \& Kemp, S. (1998). NEPSY: A developmental neuropsychological assessment: Manual. San Antonio, Texas: Psychological Corporation.

Krol, N. P., De Bruyn, E. E., Coolen, J. C., \& van Aarle, E. J. (2006). From CBCL to DSM: A comparison of two methods to screen for DSM-IV diagnoses using CBCL data. Journal of Clinical Child and Adolescent Psychology, 35, 127-135.

Lehmann, M., \& Hasselhorn, M. (2007). Variable memory strategy use in children's adaptive intratask learning behavior: Developmental changes and working memory influences in free recall. Child Development, 78, 1068-1082.

Martinussen, R., Hayden, J., Hogg-Johnson, S., \& Tannock, R. (2005). A meta-analysis of working memory impairments in children with attention-deficit/hyperactivity disorder. Journal of the American Academy of Child and Adolescent Psychiatry, 44, $377-384$.

McNamara, D. S., \& Scott, J. L. (2001). Working memory capacity and strategy use. Memory and Cognition, 29, 10-17.

Meichenbaum, D. (1977). Cognitive behaviour modification, an integrative approach. New York: Plenum Press.

Melby-Lervåg, M., \& Hulme, C. (2013). Is working memory training effective? A meta-analytic review. Developmental Psychology, 49, 270-291.

Melchers, P., \& Preuss, U. (1991). K-ABC interpretationshandbuch. Amsterdam: Swets and Zeitlinger. 
Meltzer, L. (2007). Executive function difficulties and learning disabilities: Understandings and misunderstandings. In L. Meltzer (Ed.), Executive function in education: From theory to practice (pp. 77-105). New York: Guilford.

Moely, B. E., Hart, S. S., Leal, L., Santulli, K. A., Rao, N., Johnson, T., \& Hamilton, L. B. (1992). The teacher's role in facilitating memory and study strategy development in the elementary school classroom. Child Development, 63, 653-672.

O'Neill, M. E., \& Douglas, V. I. (1996). Rehearsal strategies and recall performance in boys with and without attention deficit hyperactivity disorder. Journal of Pediatric Psychology, 21, 73-88.

Oh, S. H., \& Kim, M. S. (2004). The role of spatial working memory in visual search efficiency. Psychonomic Bulletin \& Review, 11, 275-281.

Paris, S. G., \& Oka, E. R. (1986). Children's reading strategies, metacognition and motivation. Developmental Review, 6, 25-56.

Poole, B. J., \& Kane, M. J. (2009). Working-memory capacity predicts the executive control of visual search among distractors: The influences of sustained and selective attention. Quarterly Journal of Experimental Psycholology, 62, 1430-1454.

Pressley, M., \& Levin, J. R. (1977). Task parameters affecting the efficacy of a visual imagery learning strategy in younger and older children. Journal of Experimental Child Psychology, 24, 53-59.

Rapport, M. D., Alderson, R. M., Kofler, M. J., Sarver, D. E., Bolden, J., \& Sims, V. (2008). Working memory deficits in boys with attention-deficit/hyperactivity disorder (ADHD): The contribution of the central executive and subsystem processes. Journal of Abnormal Child Psychology, 36, 825-837.

Rapport, M. D., Orban, S. A., Kofler, M. J., \& Friedman, L. M. (2013). Do programs designed to train working memory, other executive functions, and attention benefit children with ADHD? A meta-analytic review of cognitive, academic, and behavioral outcomes. Clinical Psychology Review, 33, 1237-1252.

Rohwer, W. D., Raines, J. M., Eoff, J., \& Wagner, M. (1977). The development of elaborative propensity in adolescence. Journal of Experimental Child Psychology, 23, 472-492.

Roth, R. M., Wishart, H. A., Flashman, L. A., Riordan, H. J., Huey, L., \& Saykin, A. J. (2004). Contribution of organizational strategy to verbal learning and memory in adults with attention-deficit/hyperactivity disorder. Neuropsychology, 18, 78-84.

Rugg, M. D., \& Curran, T. (2007). Event-related potentials and recognition memory. Trends in Cognitive Sciences, 11, 251-257.

Rugg, M. D., \& Wilding, E. L. (2000). Retrieval processing and episodic memory. Trends in Cognitve Sciences, 4, 108-115.

Sander, M. C., Werkle-Bergner, M., Gerjets, P., Shing, Y. L., \& Lindenberger, U. (2012). The two-component model of memory development, and its potential implications for the educational setting. Developmental Cognitive Neuroscience, 25, S67-S77.

Schleepen, T. M. J., \& Jonkman, L. M. (2012). Children's use of semantic organization strategies is mediated by working memory capacity. Cognitive Development, 27, 255-269.

Schleepen, T. M. J., \& Jonkman, L. M. (2014). A longitudinal study of semantic grouping strategy use in 6-12 year-old children: Investigating developmental phases, strategy transfer and the role of working memory. The Journal of Genetic Psychology, Research and Theory on Human Development, 175, 451-471.

Schleepen, T. M. J. Markus, C. R., \& Jonkman, L. M. (2014). Dissociating the effects of semantic grouping and rehearsal strategies on Event-Related Brain Potentials. International Journal of Psychophysiology, 94, 319-328.

Scholte, E. M., van Berckelaer-Onnes, I. A., \& van der Ploeg, J. D. (2001). DSM-IV related ADHD symptom ratings by professional caretakers in residential treatment centres. Journal of Child Psychology and Psychiatry, 42, 341-346. 
Seli, P., Carriere, J. S. A., Thomson, D. R., Cheyne, J. A., Ehgoetz Martens, K. A. \& Smilek, D. (2014). Restless mind, restless body. Journal of Experimental Psychology: Learning, Memory, and Cognition, 40, 660-668.

Semlitsch, H. V., Anderer, P., Schuster, P., \& Presslich, O. (1986). A solution for reliable and valid reduction of ocular artifacts, applied to the P300 ERP. Psychophysiology, 23, $695-703$.

Shing, Y. L., Werkle-Bergner, M., Li, S-C., \& Lindenberger, U. (2008). Associative and strategic components of episodic memory: A life-span dissociation. Journal of Experimental Psychology: General, 137, 495-513.

Shipstead, Z. Redick, T. S., \& Engle, R. W. (2012). Is working memory training effective? Psychological Bulletin, 138, 628-654.

Skodzik, T., Holling, H., \& Pedersen, A. (2013). Long-term memory performance in adult ADHD: A meta-analysis. Journal of Attention Disorders. doi:10.1177/1087054713510561

Spreen, O., \& Strauss, E. (1998). A compendium of neuropsychological tests: Administration, norms and commentary. New York: Oxford University Press.

St Clair-Thompson, H. L., Stevens, R., Hunt, A., \& Bolder, E. (2010). Improving children's working memory and classroom performance. Educational Psychology, 30, 203-219.

Stevens, J. (2005). Working memory in children with ADHD. In D. Gozal \& D. L. Molfese (Eds.), Attention deficit hyperactivity disorder: From genes to patients (pp. 277-292). Totowa, NJ: Humana Press.

Swing, S. R., Stoiber, K. C., \& Peterson, P. L. (1988). Thinking skills versus learning time: Effects of alternative classroom-based interventions on student's mathematics problem solving. Cognition and Instruction, 5, 123-191.

Timmerman, K. (2004). Kinderen met aandachts- en werkhoudingsproblemen. Leuven/Voorburg: Acco.

Timmerman, K., \& van der Schoot, D. (2001). Kinderen met geheugen en inprentingsproblemen. Leuven, Leusden: Acco.

Turley-Ames, K. J., \& Whitfield, M. M. (2003). Strategy training and working memory task performance. Journal of Memory and Language, 49, 446-468.

Vilberg, K. L., Moosavi, R. F., \& Rugg, M. D. (2006). The relationship between electrophysiological correlates of recollection and amount of information retrieved. Brain Research, $1122,161-170$.

Vilberg, K. L., \& Rugg, M. D. (2007). Dissociation of the neural correlates of recognition memory according to familiarity, recollection, and amount of recollected information. Neuropsychologia, 45, 2216-2225.

Voelker, S. L., Carter, R. A., Sprague, D. J., Gdowski, C. L., \& Lacher, D. (1989). Developmental trends in memory and metamemory in children with attention deficit disorder. Journal of Pediatric Psychology, 14, 75-88.

Waters, H. S. (2000). Memory strategy development: Do we need yet another deficiency? Child Development, 71, 1004-1012.

Whitaker, A. M., Bell, T. S., Houskamp, B. M., \& O' Callaghan, E. T. (2015). A neurodevelopmental approach to understanding memory processes among intellectually gifted youth with attention-deficit hyperactivity disorder. Applied Neuropsychology: Child, 4, $31-40$.

Wilding, E. L. (2000). In what way does the parietal ERP Old/New effect index recollection? International Journal of Psychophysiology, 35, 81-87.

Willcutt, E. G., Doyle, A. E., Nigg, J. T., Faraone, S. V., \& Pennington, B. F. (2005). Validity of the executive function theory of attention deficit-hyperactivity disorder: A meta-analytic review. Biological Psychiatry, 57, 1336-1346.

Woodman, G. F., \& Luck, S. J. (2004). Visual search is slowed when visuospatial working memory is occupied. Psychonomic Bulletin \& Reviews, 11, 269-274. 